\title{
Irinotecan/P-glycoprotein Inhibitor HM30181AK Combination Tablet
}

National Cancer Institute

\section{Source}

National Cancer Institute. Irinotecan/P-glycoprotein Inhibitor HM30181AK Combination

Tablet. NCI Thesaurus. Code C88280.

An orally bioavailable combination tablet containing the semisynthetic camptothecin derivative irinotecan and the multidrug resistance (MDR) efflux pump P-glycoprotein (Pgp) inhibitor HM30181AK, with potential antineoplastic activity. HM30181A binds to P-gp and prevents the P-gp-mediated efflux of irinotecan from tumor cells, which may result in greater intracellular concentrations of irinotecan and enhanced cytotoxicity. Retained intracellularly, the prodrug irinotecan is converted, by a carboxylesterase-converting enzyme, to the biologically active metabolite 7-ethyl-10-hydroxy-camptothecin (SN-38). SN-38 inhibits topoisomerase I activity by stabilizing the cleavable complex between topoisomerase I and DNA, resulting in DNA breaks that inhibit DNA replication and trigger apoptotic cell death. P-gp, encoded by the MDR-1 gene, is a member of the ATPbinding cassette $(A B C)$ superfamily of transmembrane transporters and is overexpressed by some MDR tumors, preventing the intracellular accumulation of various cytotoxic agents. 